CHINA AND ITS CONTACTS WITH THE WIDER WORLD: A PERSPECTIVE SEEN THROUGH EXPORT WARES*

Throughout history, China has had significant international contacts, mostly with neighbouring countries, but its reach has continued to grow and is very significant today. Trade has been one of the most important vehicles of this dialogue; Chinese manufactured objects have made their way to almost everywhere in the world. Historically, besides silk, Chinese ceramics and porcelains were without doubt the most popular trade goods. Not only did other cultures attempt to imitate them, but Chinese manufacturers were also influenced by their trade partners; together they weave a complicated net of transcultural interaction.

From April 28th, the Rijksmuseum Amsterdam presents, for a short time, an insight into the world created by trade; through a selection of export wares from its collection of Asian Art, focusing on China and her contacts with other cultures. This new display will cover a number of significant aspects and is subdivided into four sections.

\title{
1 China and Central Asia
}

The contact between China and Central Asia can be traced back at the latest to the Han dynasty (202 BC-220 AD). Goods were exchanged along the Silk Road through intermediate traders. Archeological finds such as those from the well-known excavation at Samarra confirm that by the 9th century Persian 8 Iranian potters were already imitating Chinese ceramics. To demonstrate this relationship, the new display will contrast a Chinese example of Northern Song (960-1125) yingqing ware ${ }^{1}$ and its Iranian imitation ${ }^{2}$, as well as a blue and white dish decorated with the wave and grapes patterns of the Yongle period (1402-1424) and its 16th century Iznik imitation. ${ }^{3}$ However, this interaction was not just one way; ceramic production in Central Asia also influenced Chinese ceramics. The curious form of a Chinese blue and white ewer from the second half of the 15 th century ${ }^{4}$ can be explained as an imitation of an Islamic leather water carrier (similar imitations are also known in bronze from India and Indonesia). Additionally, we will show a Zhengde period (1506-1521) flower vase ${ }^{5}$ with the Arabic inscription: 'May Allah grace his kingdom by preserving its prosperity for as long as it lasts.' These two objects were obviously made in China especially for the Islamic market.

\section{China and Southeast Asia}

Southeast Asia has a long history of political, economic, and diplomatic contact with China. Vietnam and Thailand have played the most important roles, not only because they sent regular tribute missions to China but $_{6}$ alds. $0_{3}$ 02:51:22PM 

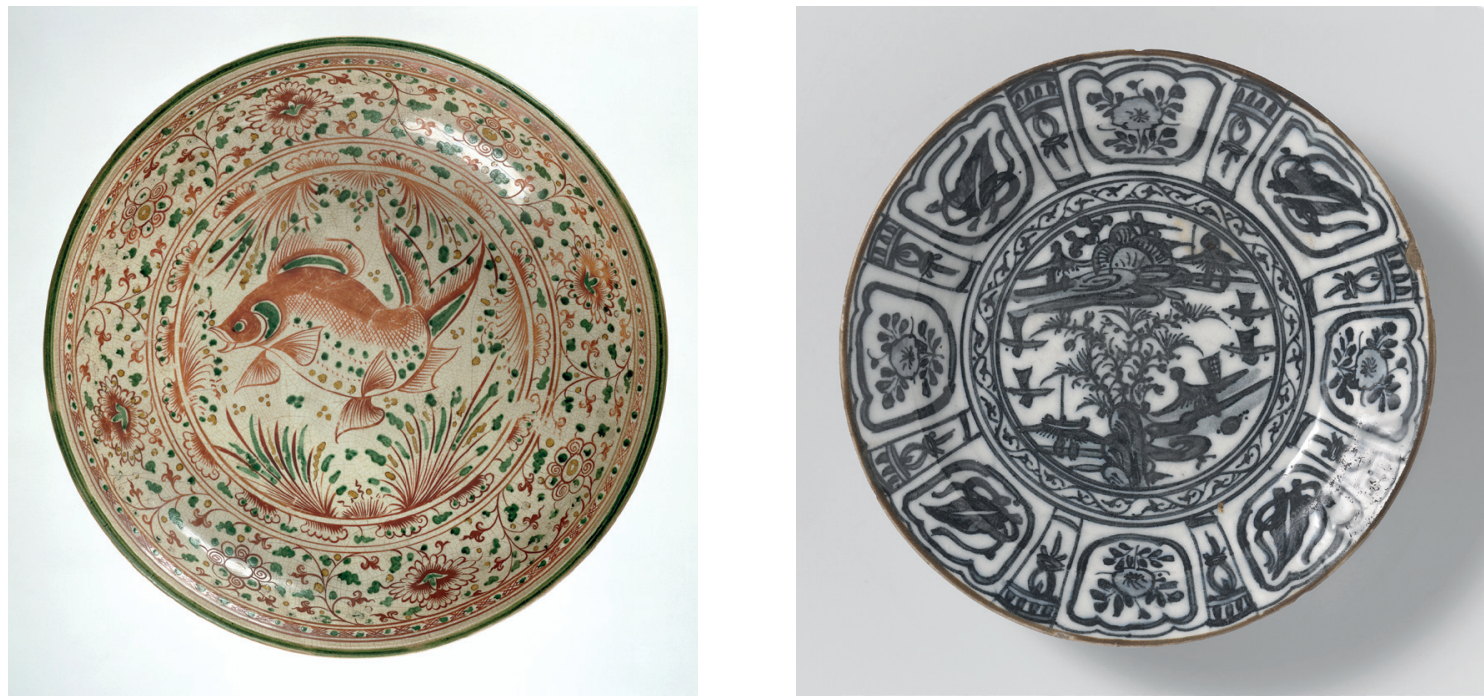

Fig. 1 (left)

Dish, stoneware, decorated in overglaze yellow, green and red, d. 45,5 cm., Vietnam, 15th century, Rijksmuseum Amsterdam, inv.nr. AK-RAK-1978-1.

Fig. 2 (right)

Dish, stoneware,

decorated with

landscape in blue and white, Kirman, Kuwait, 17th century, Rijksmuseum Amsterdam, inv.nr. BK-

NM-12419. because they were important markets for Chinese ceramics. Moreover, they were also stages on the route of the Chinese maritime expeditions led by Zheng He (1371-1433) from 1405 to 1433 . On display will be Swatow wares, ${ }^{6}$ made in Fujian province, which were broadly distributed to Indonesia, the Philippines, Japan, and mainland Southeast Asia. A painted jar in red and green enamels ${ }^{7}$ shows its relationship with two Vietnamese stoneware vessels decorated in yellow, green and red (fig. 1). ${ }^{8}$ These Swatow wares and the related Vietnamese stonewares were called Annamde and were often selected for use in the Japanese tea ceremony. Chinese Celadon was also a favoured product in the Southeast Asian market, especially longquan wares made in Zhejiang province, which were also imitated in Thai and Vietnamese potteries. The new display will give an opportunity to compare the similarities and differences between the glaze and shape of Chinese longquan and Thai Sawankhalok ware. ${ }^{9}$ We will also present a product especially made to meet the need of China's Southeast Asian customers: an 18th century painted enamel bowl with a cover ${ }^{10}$ that is decorated with traditional Thai patterns, clearly demonstrating a commission from the Thai market.

\section{3 ‘Kraak' in a Global Context}

Chinese porcelain called Kraak was one of the major items that the Dutch East India Company (VOC) imported from Asia. The popularity and the huge demand for Chinese Kraak soon drew Japanese competitors to create imitations. In fact this was not limited to Japan, but potters from the Islamic world were also drawn to this market. The exhibition will show Chinese and Japanese Kraak porcelains and an imitation from Kuwait (fig. 2) showing the tensions and competition in the global trade market of the 17th and 18th centuries. ${ }^{11}$

\section{China and Europe}

In examining the relationship between China and Europe, Dutch merchants and the VOC played a crucial role. Special ofders were sent directly from $\boldsymbol{m}_{2023}$ 02:51:22PM 


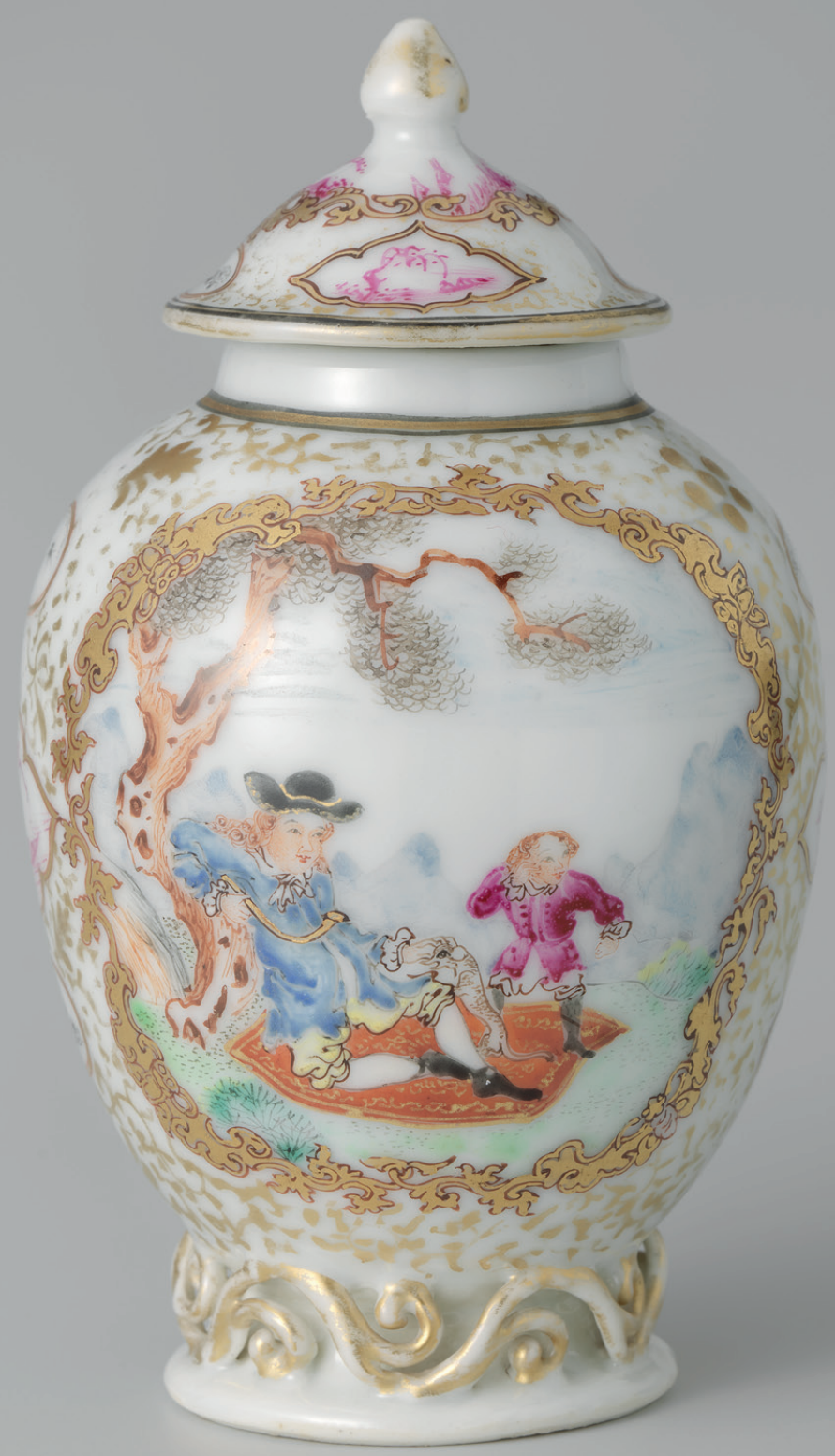


Fig. 3

Teapot, porcelain decorated in overglaze enamels of famille rose palette and gold, h. $13 \mathrm{~cm}$., China, ca. 1740-1745, Rijksmuseum Amsterdam, inv.nr. AK-RAK-2014-5. the VOC to workshops in China. This can be seen on porcelain that carries the coat of arms of Amsterdam and the Kingdom of Holland. ${ }^{12}$ As Chinese porcelain was considered rare and exotic by its European consumers, the image of Europeans was also exotic to the Chinese. In this exhibition, the viewer will discover images of Europe depicted on Chinese porcelain, on a literati's table-screen, and even on ivory sculptures. ${ }^{13}$ Chinese porcelain fascinated European collectors, and European factories finally succeeded in creating their own porcelain products in 1710 at Meissen in Germany. However, the demand for Chinese porcelain in Europe did not abate, and in fact circa 1740 a clever Chinese pottery began producing imitations of the Meissen style to compete (fig. 3). ${ }^{14}$

We are all familiar with China's manufactured goods in our homes and offices today. This display hopes to provide its viewers with an historical perspective and show through these objects that Chinese trade is by no means a recent phenomenon.

- Ching-Ling Wang is curator of ancient Chinese art, Staatliche Museen zu Berlin Preußischer Kulturbesitz, Museum für Asiatische Kunst.

\section{Notes}

* On display from 28th April 2015 temporarily, curated by Jan van Campen, Menno Fitski, William Southworth and Ching-Ling Wang.

1. AK-MAK-1271.

2. AK-MAK-1477.

3. BK-1960-170.

4. AK-RAK-1982-2.

5. AK-RAK-1973-16.

6. AK-MAK-647, AK-MAK-328.

7. AK-MAK-328.

8. AK-RAK-1978-1, AK-RAK-1978-2.

9. AK-MAK-1182, AK-MAK-219.

10. AK-MAK-1226.

11. BK-NM-13086, AK-RBK-1977-255, AK-RAK-1971-4, BK-NM-12419.

12. AK-NM-13588, AK-MAK-1733, AK-RBK-15910.

13. NG-1994-12, AK-RAK-2014-5, AK-RAK-2003-3, NG-407, AK-MAK-368, AK-RAK-2006-4.

14. AK-2014-5. 


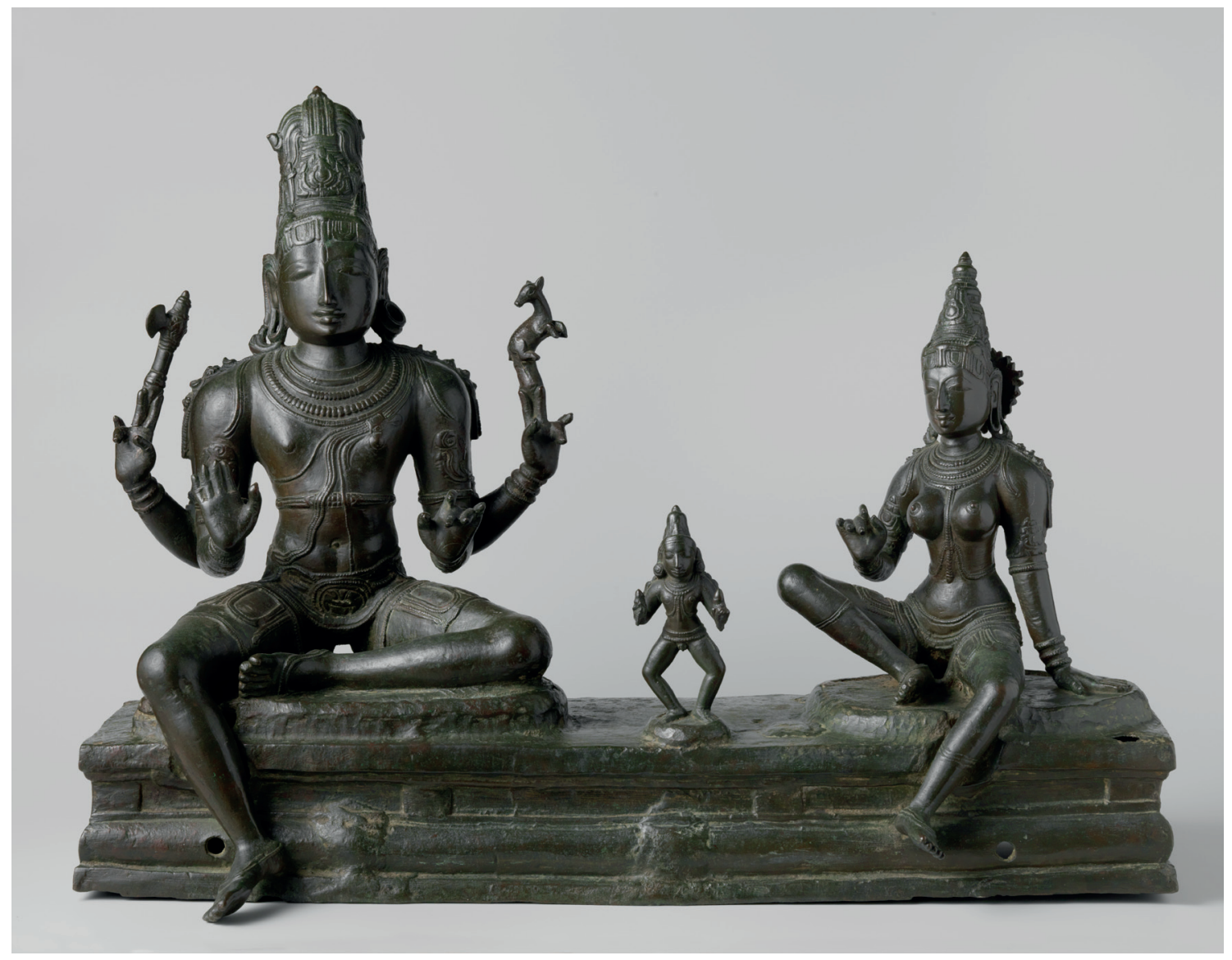

Afb. 1

Somaskanda, brons,

47,1 x 64,5cm., India,

Tamil Nadu, $12^{\mathrm{e}}$ eeuw,

Rijksmuseum Amsterdam,

inv.nr. AK-RAK-2012-1. 